\title{
MYTH AND REALITY OF ENTREPRENEURIAL UNIVERSITIES IN IRAN
}

\author{
Reza Mahdi \\ Asst. Prof. of Institute for Cultural and Social Studies (ISCS), IRAN, iamahdi@yahoo.com
}

\begin{abstract}
Development of infrastructures and facilities shows has started entrepreneurship journey in Iranian scientific system. Development of infrastructures and facilities represents the beginning of entrepreneurship journey in Iranian scientific system. However, Iranian entrepreneurial university is not myth, but it has not been come true yet, especially in the field of social entrepreneurship. The current situation of university represents or indicates the complex and challenging journey ahead and suggests initiatives to transform Iranian universities into more entrepreneurial institutions. There are two main necessary conditions for this vital journey. One, Iranian universities not only must pay close attention to the coherence between them and the environment, but also, they should avoid the ivory tower attitude and take into careful consideration about the specificities of their context and the needs of the stakeholders. Second, it is need to change academic culture and attitudes and promote and diffuse entrepreneurial culture and entrepreneurial values within each institution. Changing in academic culture and attitudes is second point, universities should promote and diffuse entrepreneurial culture and values within each institution. Turning the traditional university into an entrepreneurial university is a cultural matter, and it needs entrepreneurship training, especially skills training to individuals. Based on this study, shaping and effectiveness of entrepreneurial university don't possible without systematic development of skill training and entrepreneurial education for students, faculty members, managers and staff, and reinforcement of entrepreneurial attitudes in university human resources. Also, the main weakness of academic entrepreneurship is overemphasis of economic-technical entrepreneurship dimensions and low attention on socio-cultural entrepreneurship. One of the key perspectives of the third generation university is development of professional skills and competences and empowerment of students and faculty in direction of national development process and society problems solving. In the academic entrepreneurship journey, we should eliminate weaknesses, strength strengths and increase universities responsibility and accountability. Entrepreneurial university and the 3G University should serve society in socio-economic dimensions.
\end{abstract}

Keywords: Higher Education, Entrepreneurial University, Socio-economic Entrepreneurship.

\section{INTRODUCTION}

Technology is a game for the rich, a dream for the poor, and a key for the wise, technology is the master key for development (Sharif, 1983). Science and technology is the engine and innovation and entrepreneurship is jet engine to sustainable development, and they are also the major solution to the socio-economic growths, crisis and progresses. Science, technology and innovation are connected rings in synergy chain of science and wealth. Looking back at the development (modernization) history, most great revolution was closely linked with transformative breakthroughs in S\&T, which had a far-reaching impact on the rise and fall of a nation and the destiny of a country as well (Yongxing, 2010). The countries that were able to seize the opportunity and achieve the socio-economic take-off, had taken the lead in fulfilling development. 
Contemporary modern societies are formed based on successful technology, most of them have been established based on scientific discoveries. Technology is considered the product of new development of human civilization, determining of essential element in social, economic and political exchanges in the communities. It is expression of advancement level, empowerment and a superior parameter of a society (Mahdi, 2015).

For national development, universities need to become more entrepreneurial, changing their strategies, their structures and their practices, changing their culture and helping students and faculty members to develop their entrepreneurial mindsets and entrepreneurial actions. But universities are professional bureaucracies focused on core missions and values in relation to education and research (the first and second generation university). Their capacity to change and adopt new behaviors seems low. This creates a paradox and tension between what universities are and what they should be to deal with the evolutionary trends and the world complexities. At the same time, there is much talk of entrepreneurial universities in both the world of science and practice. Too work has been done on entrepreneurial universities. Is there a strong relationship and connection between research on entrepreneurial universities and the needs, the awareness, the policies and the strategies of universities? Is the idea of an entrepreneurial university a myth or a reality in Iran? Even if we are convinced that universities must change and become more entrepreneurial, this question must be asked. This study responds to the question, highlighting how universities can conceive of and implement strategic changes to better promote entrepreneurship internally and externally (Fayolle \& Redford, 2014).

Despite basic differences in economic conditions and resources availability, social structures, cultural settings and historical backgrounds, higher education systems in most countries face similar challenges including maintaining research capacity, combining elite with mass higher education, offering lifelong education and providing society with a pace for the development and maintenance of critical knowledge, independent thinking, social identity and values (Guerrero, Urbano \& Salamzadeh, 2014). This act becomes more relevant during recessionary times and has gained the attention of academics, governments and policy-makers around the world. Particularly, these efforts have been encouraged because entrepreneurial universities become important catalysts for regional, economic and social development (Guerrero and Urbano, 2011; Kirby et al., 2011). The existing literature on entrepreneurial universities provides insights about the entrepreneurial transformation process of universities in developed countries and current efforts to explore it in Iran. The studies evidence that usually in Iran the first measures implemented to foster entrepreneurship within universities are usually entrepreneurship educational planes. The main explanation is the positive relationship between entrepreneurship education and entrepreneurial activity (Coduras et al., 2008). The low prevalence rate of formal and informal entrepreneurship education in Iran evidenced the need of other support measures for entrepreneurs starting business within universities (Coduras et al., 2010). Thus, in Iran, the literature on entrepreneurial universities is somewhat limited or, more accurately, rare (Etzkowitz and Mello, 2004). Based on these previous arguments, our purpose is to contribute to a better understanding of the entrepreneurial transformation process of entrepreneurial universities. To accomplish this objective, theoretically we adopted an integral entrepreneurial university. This study focuses on Iranian universities by analytical methodology and comprises four main sections including the conceptual framework, methodology, academic entrepreneurship in Iran, and conclusions. However, this study is an elementary investigation and is been depth in next studies.

\section{CONCEPTUAL FRAMEWORK OF ENTREPRENEURIAL UNIVERSITY}

Entrepreneurial university is the new generation university that has created from evolution of first and second generations. The centralization of the first generation universities is education and the second generation is education and research. The function of entrepreneurial university is socio- economic, both in individual and organizational level and does these functions through education and research. The major specifications of entrepreneurial and dynamic university are target-oriented and mission- driven, creating balance among education, research and social services, varied financial resources, helping local and national socioeconomic development and strengthening national innovation system (NIS). The major defect of the entrepreneurial university is concentrating on technical-economic entrepreneurship, neglecting from integrated entrepreneurial approach and reduction of entrepreneurial university in commercial firm level.

A entrepreneurial university is a natural incubator that endeavors to simultaneously fulfill its missions (teaching, research and entrepreneurial activities) while providing an adequate atmosphere in which the university community (academics, students and staff) can identify, explore and exploit innovative and creative ideas that could be transformed into new ventures (Kirby et al., 2011). The literature review shows an integral entrepreneurial university framework and a brief description of each construct of this framework 
(Guerrero, Urbano \& Salamzadeh, 2014). To understand how an economy works, it is necessary to know the political, social and cultural factors that establish its organizational dynamics, including its system of beliefs and decision-making processes (North, 2005). Particularly, following the influence of each entrepreneurial university's factors on academic entrepreneurship, the entrepreneurial university makes it possible to generate several direct outcomes from teaching, research and entrepreneurial activities. Outcomes could be transformed into determinants of economic development or factors of production function such as human capital (Lucas, 1988), knowledge capital (Solow, 1956; Romer, 1986), social capital (Coleman, 1988), and entrepreneurship capital, which later could produce positive impacts on the economy and society of a specific region (Urbano and Guerrero, 2013).

The entrepreneurial university must fulfill three missions simultaneously that otherwise might be at odds with one another: teaching, research and entrepreneurship (Schulte, 2004). A university's primary function has always been to teach, which provides society with graduates who become both jobseekers and job creators. Its secondary function has been to conduct research, which, within the new knowledge-based economy, not only generates published academic findings but also innovations for new companies. Now, entrepreneurial activities link research results to their practical implications for society "Fig. 1". Knowledge spillover appears to transmit university research via several conduits. Based on that, new companies are generated by the commercialization of research outputs of multidisciplinary research (Schulte, 2004).

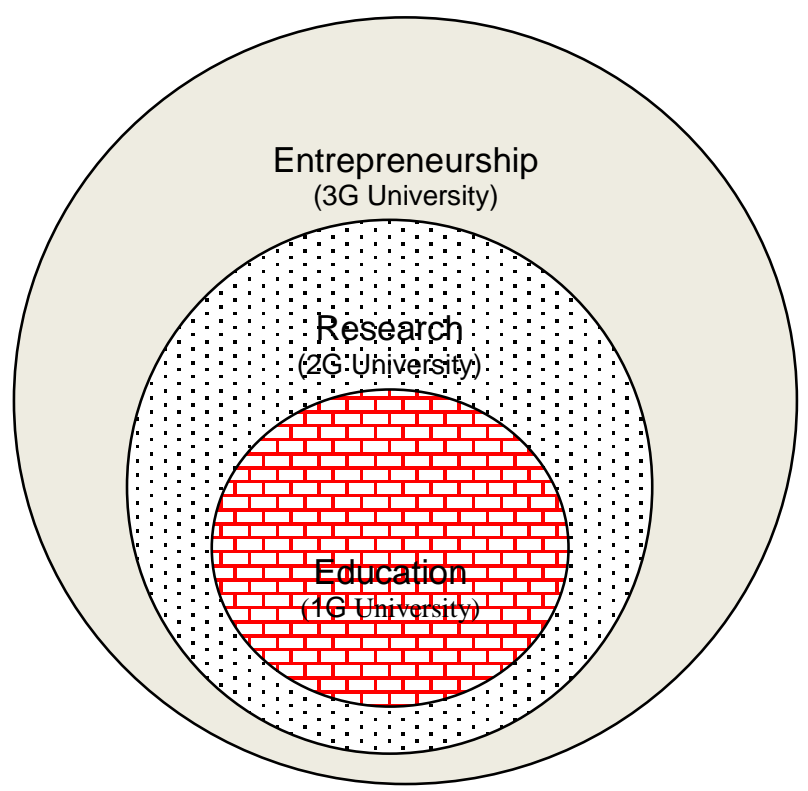

Figure1. Functions of the $3 G$ University

The institutional approach draws attention to institutional or contextual (PESTEL) ${ }^{1}$ challenges and factors as determinants of entrepreneurship (Thornton et al., 2011). North (1990) explains how institutions affect economic and social development: Institutions are the rules of the game in a society, or more formally, institutions are the constraints that shape human interaction. Specifically, institutions can be either formal (with political rules, economic rules and contracts) or informal with conduct codes, attitudes, values, norms of behaviors and conventions, essentially, the culture of a specific society. In this context, the institutional approach provides a better understanding about the environmental factors of entrepreneurial universities. According to previous investigations, the key environmental factors of entrepreneurial universities including 1) a flexible organizational and governance structure with innovative forms to help reduce the levels of bureaucracy and to support a fluid language with other agents in the region's entrepreneurial ecosystem to allow for the interaction and the definition of policies and practices to achieve their missions (O'Shea et al., 2007; Wood, 2009), 2) measures integrated by different instruments and mechanisms developed by universities to support internal and external new firm creation as centers of small-university businesses, research facilities, research groups or quasi-firms, liaison offices, technology transfer offices and incubators (Grandi and Grimaldi, 2005; Link and Scott, 2005), 3) adequate educational planes, for both students and academics, that provide a wide variety of situations, aims and methods oriented toward improving students'

\footnotetext{
${ }^{1}$ political, economic, social, technological, environmental, legal
} 
skills, attributes and behaviours (behaviors) to develop both creative and critical thinking, 4) community members' favorable attitudes toward entrepreneurship to facilitate the development of potential entrepreneurs at all university levels (Louis et al., 1989; Linan et al., 2011), 5) the existence and the diffusion of successful entrepreneurs, who will become new role models to their peers, demonstrating that entrepreneurial success is more than a theory and influencing entrepreneurial intentions (Linan et al., 2011), and 6) adequate reward systems that represent strategic actions intended to promote an enterprise that is both monetary (bonuses, use of corporate resources, profit-sharing, etc.) and non-monetary (promotion and recognition systems) (Kirby, 2006).

As a complementary approach, the resource-based view helps to explain the internal factors that generate a competitive advantage (Wernerfelt, 1995) within an entrepreneurial university. The main internal factors including 1) human resources, which are the most critical element for the development of educational quality and generation of innovation in research (Powers and McDougall, 2005), 2) financial resources from diversified sources of income (government, research contracts, campus services, student fees, and others) (Clark, 1998) are relevant to obtain positive and statistically significant relationships between research and development expenditures and spin-off activities (Powers and McDougall, 2005), 3) physical resources that delimit the old boundaries between the university and the external world through infrastructure designed to satisfy social demands (Clark, 1998) and that create a fertile environment for innovation and new ventures (Guerrero and Urbano, 2011), 4) strong networks that support entrepreneurial universities' activities by attracting the financial resources required for innovation and new venture creation, and 5) status and prestige representing the uniqueness of historical conditions, whereby firms as intrinsically historical and social entities can be the basis for sustained competitive advantage and can also attract investments, networks and access to public funding (O'Shea et al., 2007). Thus, entrepreneurship infrastructures and facilities have vital role in development of academic entrepreneurial and construction of entrepreneurial universities. In the study is focus on Iranian infrastructures and facilities of academic entrepreneurship. Finally, the study emphasizes that attention to economic-technical entrepreneurship must be as equivalent as socio-cultural entrepreneurship "Fig. 2".

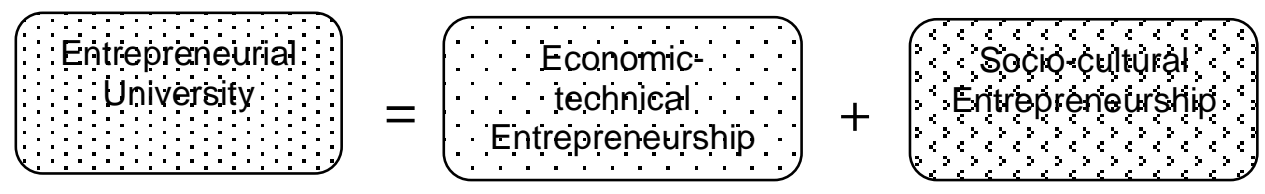

Figure2. Necessity of balanced attention to socio-economic

\section{METHODOLOGY}

Research Goal. The aim of this study is to investigate entrepreneurship of Iranian universities with using focus group technique (a group including 8 members from specialists of S\&T field in the country). In the study, with a balanced and comprehensive approach has been investigated entrepreneurial dimensions and levels of entrepreneurial universities through documental review and expert analysis. It must emphasize on entrepreneurship in socio-economic dimensions and in individual and organizational levels of academic society, academy and its departments.

Sample and Data Collection. This research isn't data-oriented, the required data and information were achieved in focus group talks and sessions. Also, it was used the results of research project on entrepreneurial university (Mahdi, 2014a). In addition, in the study was used some researches results, scientific articles and texts in the sessions of focus group. In general, the views of focus group members were been criterion to evaluate and analyze infrastructures and facilities of Iranian scientific system to develop and deploy academic entrepreneurship.

\section{IRANIAN ENTREPRENEURIAL INIVERSITIES}

Evaluating entrepreneurship of Iranian universities is a too complex subject because of wide spreading the universities and higher education institutions. For example, some people believe that Total Scientific-Applied University with 900 paradises (independent institutes) is an entrepreneurial university. But there is not an accurate assessment about entrepreneurship performance in this university. Also, we can't evaluate and judge on the entrepreneurship of Technical-Professional and Payam Noor Universities with 500 campuses (independent unites). Thus, in the study to assess and judge the entrepreneurship of Iranian universities, it is 
reviewed the entrepreneurship infrastructures of Iranian universities with socio-economic approach in three decades is reviewed. In the recent three decades, Iranian higher education system has especially emphasized on quantitative extension and education function deployment. For instance, in entrepreneurship concept as internationalization of higher education, Iranian university system has significant distance with national entrepreneurship missions. However, it was done some infrastructural actions to develop higher education and academic entrepreneurship with economical entrepreneurship approach (table 1).

Table 1. Main infrastructures and facilities for academic entrepreneurship

\begin{tabular}{|c|l|}
\hline No. & \multicolumn{1}{c|}{ infrastructures and facilities } \\
\hline 1 & $\begin{array}{l}\text { Science and technology towns, parks and incubators (table } \\
2)\end{array}$ \\
\hline 2 & The support of knowledge-based firms and innovations law \\
\hline 3 & the entrepreneurship educations \\
\hline 4 & Development of university- industry relations \\
\hline 5 & Scientific associations (table 3) \\
\hline 6 & Medical universities strategic plans \\
\hline
\end{tabular}

One of the most important infrastructural actions in the development of academic entrepreneurship is the establishment of science and technology parks and technology incubators in the most country provinces. Science and technology parks can play a main role for technology development, commercialization of research achievements, the relation of university with industry (society) and interface of research- market cycle. The first Iranian scientific and research town has been constituted in Esfahan province in 1993. Also, the first technology incubator in the Esfahan scientific and research town was constituted in 1999. The second technology park (Pardis park) has made in Tehran province in 2001. Consequently, by parting Iranian organization for research on science and technology (IROST) six science and technology parks in South Azerbaijan, Khorasan, Semnan, Fars, Markazi and Gilan provinces constructed in 2002. At present, there are more than 38 towns and parks of science and technology and more than 99 technology incubators including more than 4000 knowledge-based (spin-off) firms in Iranian science and technology system (Table 2). Of course, the construction of science and technology parks and incubators has started late in compare with other Asian industrial countries such as Japan and S. Korea.

The law of supporting knowledge-based firms and innovations is one of the responsibly interventions of Iran's government to strengthen academic entrepreneurship (approved by Iran's parliament in 2010). The outcomes of the law are: supporting knowledge-based firms, raising science and technology, commercialization of research and technology achievements, academic entrepreneurship, stay elites, research-oriented higher education, promotion of industry-university relations, growth of the share of business sector in research, raising knowledge and technology market, occupation creation for graduates and elites (Mahdi, 2014b). Therefore, this law is one of the entrepreneurship infrastructures and facilities for Iranian higher education and universities. To execute this law, it was constituted a fund (Sandoge Noavary va Shokofaee). At present, financial capital of the fund is about $€ 700$ million and this fund is supporting more than 3000 Iranian knowledge-based companies and firms. Also, Iranian government helps to this fund about $€ 60$ millions. Unfortunately, the fund's financial supports are limited to technical firms and economic entrepreneurship (more information at www.nmfund.ir).

Moreover, the entrepreneurship education is the one of the other factors to develop academic entrepreneurship that has been started since 2000s. The first course of entrepreneurship education established in management faculty of the Tehran University in 2004. Consequently, the entrepreneurship faculty in Tehran University found in 2006. Allame-Tabatabee University, After Tehran University, has been added entrepreneurship management course to the courses of management and accounting faculty. Then, Shahid Beheshti, Semnan and Zahedan universities have offered entrepreneurship courses. Of course, it is not accurately evaluated from the performance and effectiveness of entrepreneurship education. The 
performance of entrepreneurship education is assessed by some managers and professors. Moreover of the entrepreneurship direct educations, In addition to direct training in entrepreneurship there is some entrepreneurship indirect education in Iranian science and technology parks and incubators.

Table 2. Distribution of Iranian S\&T towns, parks and incubators

\begin{tabular}{|l|c|c|}
\hline \multicolumn{1}{|c|}{ Province } & S\&T towns and parks & S\&T incubators \\
\hline East Azerbaijan & 1 & 5 \\
\hline West Azerbaijan & 1 & 1 \\
\hline Ardabil & 0 & 1 \\
\hline Esfahan & 2 & 4 \\
\hline Alborz & 2 & 1 \\
\hline llam & 0 & 1 \\
\hline Razavi Khorasan & 1 & 7 \\
\hline North Khorasan & 1 & 1 \\
\hline South Khorasan & 1 & 1 \\
\hline Semnan & 2 & 5 \\
\hline Gilan & 1 & 5 \\
\hline Hormozgan & 2 & 4 \\
\hline Mazandaran & 1 & 4 \\
\hline Kerman & 1 & 3 \\
\hline Markazi & 1 & 3 \\
\hline Sistan \& Balochestan & 0 & 3 \\
\hline Zanjan & 1 & 2 \\
\hline Kermanshah & 1 & 2 \\
\hline Hamedan & 1 & 2 \\
\hline Boshehr & 1 & 1 \\
\hline Khozestan & 1 & 1 \\
\hline Qazvin & 1 & 1 \\
\hline Kordestan & 0 & 1 \\
\hline Qom & 0 & 1 \\
\hline Golestan & 0 & 1 \\
\hline Lorestan & 1 & 99 \\
\hline Chahar mahal \& & 0 & 1 \\
Bakhteyary & & \\
\hline Yazd & 38 & \\
\hline Total & & 1 \\
\hline
\end{tabular}

Development of university- industry relations is the other flourishes of entrepreneurship deployment especially in universities of technology and technical-engineering disciplines. Presidents of technology universities including engineering faculty of Tehran University, Amirkabir University of technology, Sharif University of technology, present the promising reports on development of university- industry relations. But the study shows the university-industry relations is not suitable and require to more efforts (Mahdi, 2014a).

Scientific associations can be one of the attention indicators of academic society (students, graduates, faculty members) to entrepreneurship and socio-cultural influence. In the country, there are more than 356 scientific associations (31 associations on basic science, 96 associations on engineering science, 114 associations on humanities, 43 associations on agriculture discipline, 65 associations on interdisciplinary and 7 associations on art discipline) (table 3 ).

Table 3. Combination of Iranian scientific associations

\begin{tabular}{|l|c|c|}
\hline \multicolumn{1}{|c|}{ Scientific disciplines } & Count & Percent \\
\hline Engineering & 96 & $27 \%$ \\
\hline
\end{tabular}




\begin{tabular}{|c|c|c|}
\hline Humanities & 114 & $32 \%$ \\
\hline Agriculture & 43 & $12 \%$ \\
\hline Basic Science & 31 & $9 \%$ \\
\hline Interdisciplinary & 65 & $18 \%$ \\
\hline Art & 7 & $2 \%$ \\
\hline Total & 356 & $100 \%$ \\
\hline
\end{tabular}

In the future horizon, the universities of health and medical field have attend academic entrepreneurship and entrepreneurial university.

In the medical education evolution plan (2015) 11 packages for evolution and innovation is defined that one of the packages is transition toward the third generation universities. In this package expected achievements from transition toward entrepreneurial universities is determined: 1) Journey of medical universities to the $3 G$ universities, 2) Specifying position of medical universities in knowledge economy, 3) Minimizing dependency of medical universities to state budgets.

\section{CONCLUSION}

The modern university has experienced three different generations. The first generation universities were generally educational and education-oriented and the second generation universities were generally research and research activities-oriented. The $3 G$ universities are generally entrepreneur and entrepreneurship-oriented and solvent of society problems with scientific and systematic approach in interaction with environment. In the third generation university, entrepreneurship is axis and core mission of university system. In all scientific groups entrepreneurial education direction with nature and attitude of any scientific group, and in technical-engineering and medical groups entrepreneurial education and skill development based on needs of any scientific group and discipline must be considered. For shaping the $3 G$ universities and utilization from this generation university benefits must be in core of university and higher education strategies and policies skill training of students, faculty, managers and staff. In this paper, with explanation of concept and attitudes of entrepreneurial university position and necessity of skill training and entrepreneurial education in this university is stated through documents review and quality meta-analysis of done researches. Based on this research, shaping and effectiveness of entrepreneurial university don't possible without systematic development of skill training and entrepreneurial education for students, faculty, managers and staff, and reinforcement of entrepreneurial attitudes in university human resources. Therefore, one of the key perspectives of third generation (entrepreneurial) university is development of job and professional skills and competences and empowerment of students and faculty in direction of national development process and society problems solving by scientific method.

Based on the study, shaping and effectiveness of entrepreneurial university don't possible without systematic development of skill training and entrepreneurial education for students, faculty members, managers and staff, and reinforcement of entrepreneurial attitudes in university human resources. Therefore, one of the key perspectives of third generation university is development of job and professional skills and competences and empowerment of students and faculty in direction of national development process and society problems solving by scientific method. The entrepreneurial university in Iran is no myth, but it is not yet a fully reality. It has not been come true yet. The current situation of university reveals the complex and challenging journey ahead and suggest strategies to definitively transform universities into more entrepreneurial institutions in Iran. There are two main necessary conditions for this vital journey. There are two main conditions necessary for this vital journey to succeed. One, Iranian universities must pay close attention to the coherence between them and their environment. They must avoid the ivory tower attitude and take into careful consideration about the specificities of their context and the needs of their stakeholders. Second, it is need to change university culture and attitudes and promote and broadly diffuse entrepreneurial culture and entrepreneurial values within each university. We know the influence firm culture may have on a firm's entrepreneurial orientation and we expect entrepreneurial culture to have a strong impact on university entrepreneurial orientation and the entrepreneurial behaviors of faculty members, researchers, students. Turning the 
traditional university into an entrepreneurial university is a cultural matter, and it needs entrepreneurship training, especially skills training to individuals. In the academic entrepreneurship journey, it must eliminate weaknesses, strength strengths and increase universities responsibility and accountability. Entrepreneurial university and the third generation university should serve society in socioeconomic dimensions.

Final point, development of infrastructures and facilities shows that has begun entrepreneurship journey in Iranian universities. Development of infrastructures and facilities represents the beginning of entrepreneurship journey in Iranian scientific system. Therefore, Iranian entrepreneurial university is no myth, but it is not yet a fully reality it has not been come true yet especially on social entrepreneurship. The current university situations unveil represent the complex and challenging journey ahead and suggest initiatives to transform Iranian universities into more entrepreneurial institutions. There are two main necessary conditions for this vital journey. One, Iranian universities not only must pay close attention to the coherence between them and the environment, but also, universities should avoid the ivory tower attitude and take into careful consideration about the specificities of their context and the needs of the stakeholders. Second, it is need to change academic culture and attitudes and promote and diffuse entrepreneurial culture and entrepreneurial values within each institution. The study shows that the main weakness of academic entrepreneurship is overemphasis of economic-technical entrepreneurship and low attention on socio-cultural entrepreneurship. Therefore, in the entrepreneurship journey, we must eliminate weaknesses, strength strengths, increase universities responsibility and accountability, and emphasize on socio-cultural entrepreneurship.

\section{REFERENCE LIST}

Audretsch, D. and Lehmann E. (2005), Does the knowledge spillover theory of entrepreneurship hold for regions? Research Policy, 34(8), 191-202.

Clark, B. R. (1998), Creating Entrepreneurial Universities, Oxford: Pergamon.

Coduras, A., D. Urbano, A. Rojas and Martez S. (2008), 'The relationship between university support to entrepreneurship with entrepreneurial activity in Spain: A GEM data based analysis', International Advances in Economic Research, 14(4), 395-406.

Coduras, A., J., Levie, D. Kelley, R. Sumundsson and Schott T. (2010), Global Entrepreneurship Monitor Special Report: A Global Perspective on Entrepreneurship Education and Training, Babson Park, MA: Babson College.

Coleman, J. S. (1988), Social capital in the creation of human capital, American Journal of Sociology, 94, $95-120$.

Etzkowitz, H. \& Mello J. (2004), Rise of the Brazilian Triple Helix, International Journal of Technology Management and Sustainable Development, 2(3), 159-71.

Fayolle A. \& Redford, D. T. ( 2014), Introduction: towards more entrepreneurial universities - Myth or Reality, Handbook on the entrepreneurial university, University of Melbourne, 1-10.

Grandi, A. and Grimaldi R. (2005), Academics' organizational characteristics and the generation of successful business ideas, $\mathrm{J}$ of Business Venturing, 20(6), 821-45.

Grimaldi, R., M. Kenney, D. Siegel and Wright M. (2011), 30 years after Bayh-Dole: Reassessing academic entrepreneurship', Research Policy, 40(8), 1045-57.

Guerrero, M. and Urbano D. (2011), The Creation and Development of Entrepreneurial Universities in Spain: An Institutional Approach, New York: Nova Science Publishers, Inc.

Guerrero, M. and Urbano D. (2012), The development of an entrepreneurial university, J of Technology Transfer, 37(1), 43-74.

Guerrero M., Urbano D. \& Salamzadeh A. (2014), Evolving entrepreneurial universities: experiences and challenges in the Middle Eastern context, Handbook on the entrepreneurial university, University of Melbourne, 163-187.

Kirby, D. A. (2006), Creating entrepreneurial universities in the UK: Applying entrepreneurship theory to practice, J of Technology Transfer, 31(5), 599-603.

Kirby, D. A., M. Guerrero and Urbano D. (2011), the theoretical and empirical side of entrepreneurial universities: An institutional approach', Canadian Journal of Administrative Sciences, 28(3), 302-16.

Linan, F., D. Urbano and Guerrero M. (2011), Regional variations in entrepreneurial cognitions: Start-up 
intentions of university students in Spain, Entrepreneurship and Regional Development, 23(3), 187215.

Link, A. and Scott J. (2005), 'Opening the ivory tower's door: An analysis of the determinants of the formation of U.S. university spin-off companies, Research Policy, 34(7), 1106-12.

Louis, K.S., D. Blumenthal, M.E. Gluck and Stoto M.A. (1989), Entrepreneurs in academe: An exploration of behaviors among life scientists, Administrative Science Quarterly, 34(1), 110-31.

Lucas, R. J. (1988), On the mechanics of economic development, Journal of Monetary Economics, 22(1), 342.

Mahdi Reza (2014a), Entrepreneurship University with Total Approach, research project, Tehran, Institute for Cultural and Social Studies.

Mahdi, Reza (2014b), Capacity making for academic entrepreneurship and skill-learning by the supporting knowledge-based firms law, J. of Maharat Amozi, 2(6): 24-38.

Mahdi Reza (2015), Evaluation of National Science and Technology Policies in Iran, Elsevier, ProcediaSocial and Behavioral Sciences, 195, p. 210-219.

North, D. C. (1990), Institutions, Institutional Change and Economic Performance, Cambridge, UK: University Press.

North, D.C. (2005), Understanding the Process of Economic Change, Princeton, NJ: Princeton University.

O'Shea, R.P., T. J. Allen, K.P. Morse, C. O'Gorman and Roche F. (2007), Delineating the anatomy of an entrepreneurial university: Massachusetts Institute of Technology experience, R\&D Mgn, 37(1), 1-16.

Powers, J. and McDougall P. P. (2005), University start-up formation and technological licensing with firms that go public: A resource-based view of academic entrepreneurship, Journal of Business Venturing, 20(3), 291-311.

Romer, P. (1986), Increasing returns and long-run growth, Journal of Political Economy, 94(5), 1002-37.

Schulte, P. (2004), 'The entrepreneurial university: A strategy for institutional development', Higher Education in Europe, 29(2), 187-91.

Sharif M. Nawaz (1983), Management of Technology Transfer and Development, India, UN, ESCAP.

Solow, R. (1956), 'A contribution to the economic growth theory', Quarterly Journal of Economics, 70(1), 6594.

Thornton, P., D. Ribeiro-Soriano and Urbano D. (2011), Socio-cultural factors and entrepreneurial activity: An overview, International Small Business Journal, 29(2), 105-18.

Urbano, D. and Guerrero M. (2013), Entrepreneurial universities: Socioeconomic impacts of academic entrepreneurship in a European region, Economic Development, DOI: 10.1177/0891242412471973.

Wernerfelt, B. (1995), the resource-based view of the firm: Ten years after, Strategic Management J., 16(3), $171-4$.

Wood, M. (2009), does one size fit all? The multiple organizational forms leading to successful academic entrepreneurship, Entrepreneurship Theory and Practice, 33(4), 929-947.

Yongxing LU (2010), Science and Technology in China: A Roadmap to 2050, Strategic General Report of the Chinese Academy of Sciences Science Press Beijing and Springer-Verlag Berlin Heidelberg. 